\title{
Antibiotics susceptibility patterns of bacterial isolates from clinical samples in Thamar, Yemen.
}

\author{
Abdelmalek M. Amran and Abdulaziz A. Abbas \\ Department of Biotechnology and Food Technology, Faculty of Agriculture and Veterinary Medicine, Thamar \\ University, Yemen. \\ Corresponding author: Alrgma@yahoo.com
}

\begin{abstract}
This study was designed to determine the antimicrobial sensitivity patterns of some bacterial isolates from patients visited different hospitals and medical laboratories in Thamar city, Yemen. One hundred -twenty four bacterial isolates were isolated from various clinical samples namely blood (62), urine (38), stool (35) and analyzed using standard microbiology technique in the Department of Biotechnology and food technology, Faculty of Agriculture and Veterinary Medicine, Thamar University. Pathogenic bacteria were identified by their colonial morphology, Gram staining, appropriate biochemical test and API20E. Among the 135 different clinical samples collected 124 Pathogenic bacteria were isolated which includes; Salmonella typhi(33), Salmonella. paratyphi(13), Escherichia coli (34), Klebsiella pneumoniae. (22), Shigella Spp.(11), Salmonella Sp.(6), Citrbacteir freundi(3), Enterobacter Sp.(2). Antibiotics susceptibility studies showed that all Salmonella typhi isolates were high resistance to rates Lincomycin,Tetracycline whereas most of them were resistance to ,Rifampicin(87.5\%) and Nalidixic acid(50\%). Intermediate resistance was observed to Ciprofloxacin(72.7\%) and Norfloxacin(62.5\%) while, All pathogenic isolates were susceptible to Amoxicillin, Doxycycline,Streptomycin, Gentamycin. All Salmonella paratyphi isolates showed resistance to Lincomycin, Tetracycline, Streptomycin(84.6\%) and Nalidixic acid(76.9\%) but susceptible (100\%) to Amoxicillin, Doxycycline and Gentamycin(84.6\%). All Escherchia coli isolates showed high resistance to Ampicillin,Erythromycin, Lincomycin, Amoxicillin and ,Rifampicin whereas, (67.6\%) of them were resistance to Ciprofloxacin, Tetracycline, Doxycycline, Streptomycin, Gentamycin(58.8\%) and Nalidixic acid(50\%). All Klebsiella pneumoniae isolates showed high resistance to Erythromycin, Lincomycin ,Rifampicin , Streptomycin and (72.7\%) to Amoxicillin and Ciprofloxacin. All Shigella Sp. isolates showed high resistance to Erythromycin, Lincomycin, Rifampicinand Gentamycin, also to Tetracycline(90.9\%), Ampicillin(81.8\%),Amoxicillin(72.7\%) but less resistance to Doxycycline(54.5\%). Most of Shigella $S p$. isolates were susceptible to Norfloxacin(72.7\%) and Ciprofloxacin(63.6\%). All non-typhoid Salmonella Sp. isolates were multi drug resistant to the antibiotics tested. High rates of drug resistance were found in most of the isolates studied and this could be attributed to their prevailing usage and abuse in the area under study. These results suggest that multi-drug resistance among clinical pathogens is common and significant in Yemen and call for nationwide surveillance programme to monitor microbial trends and antimicrobial resistance patterns in Yemen.
\end{abstract}

Keywords: Pathogenic bacteria, antibiotic susceptibility and clinical samples.

\section{Introduction}

Resistance to commonly-prescribed antibiotics is an expanding global problem and has been observed in both developed and developing countries (Finch, 1998. Farrar, 1985, Rahal et.al.,1997 and Tenvor and Hughes, 1996) . Resistance has emerged even to newer, more-potent antimicrobial agents( Parry, 1989). A number of epidemics have recently occurred caused by multiply resistant microorganisms. The widespread use of broad-spectrum antibiotics has led to the emergence of nosocomial infections caused by drug resistant microbes (Courvalin and Weber, 2005; Chikere et al., 2008). In Yemen typhoid fever and bacterial infections of the urinary and gastrointestinal tract are common and represent a frequent cause of morbidity in outpatients as well as a frequent cause of nosocomial infections in many hospitals.

Most infections are treated on an empirical basis. Clinical experience has indicated the presence of numerous cases resistant to conventional chemotherapy. Microbial resistance rates to commonly prescribed antibiotics have increased recently (Power, 2004).

Updated knowledge of the prevailing causal bacteria and their susceptibility patterns is important for the proper selection and use of antimicrobial drugs and for the development of an appropriate prescribing policy. Furthermore, history has taught us that if we do not use antibiotics carefully, they will lose their efficacy. As a response to these challenges, the present study was designed to determine the antibiotic sensitivity pattern of pathogenic bacteria isolated from hospitalized patients in Thamar city,Yemen.

\section{Materials and Methods}

\section{Sample collection}

Blood Sample were collected aseptically from patients visited of Thamar general hospital and Taiba hospital 
in Thamar city. A total of 62 blood samples were collected from patients who were suspected of having typhoid fever according to presumptive diagnosis by a medical practitioner. Stool and urine samples were collected aseptically from Patients visited of Thamar general hospital, Taiba hospital,Mussali hospital and Aljarfi,Aziz,Alfa,Bynon medical laboratories in Thamar city. A total of 35 stool sample and 38 urine sample were collected from patients who suffering from diarrhea and urinary tract infection(UTI). All samples were collected in sterile disposable containers and analyzed at laboratory of Biotechnology and food technology Dept. Faculty of Agriculture and Veterinary Medicine, Thamar University.

\section{Sample preparation and enrichment}

$2 \mathrm{ml}$ of blood samples were inoculated onto tubes contained fluid thioglycolate medium(Himedia,India) and incubated for $48 \mathrm{hr}$ at $37^{\circ} \mathrm{C}$ for enrichment of Salmonella Spp.. Stool samples and urine samples were inoculated onto tubes contained peptone water and incubated for $24 \mathrm{hr}$ at $37^{\circ} \mathrm{C}$.

\section{Isolation}

The tubes were examined daily for evidence of bacteria growth, including

Turbidity. Subcultures were as follows: from each positive blood tube, First: a loopfull was transferred to MacConkey agar, Salmonella-Shigella agar(S.S agar) and Xylose lysine desoxycholate agar (Himedia,India ), streaked, incubated for $24-48$ hours at $37^{\circ} \mathrm{C}$. Stool samples were cultured on MacConkey agar and Salmonella-Shigella agar(S.S agar) and incubated for 48 hours at $37^{\circ} \mathrm{C}$. Urine samples were cultured on blood agar, Salmonella-Shigella agar(S.S agar)and MacConkey agar and incubated for 48 hours at $37^{\circ} \mathrm{C}$. The isolates were stained by Gram stain and examined by light microscope(Collee et.al.,1996).

\section{Identification}

124Isolates from cases with significant bacteria were purified and identified as follows:

\section{Biochemical tests}

Important biochemical tests (Oxidase test, SIM test, Urease test, Methyl Red/ Voges-Proskauer test, Citrate utilization, TSI test, and Catalase test) were conducted according to(Collee et.al.,1996, Baron. and Finegold, 1990 and Forbes et.al.2007 ).

\section{Api20E system}

Identification of isolates was confirmed by biochemical tests on API 20 strips(BioMerieux, France). This system is devised for the biochemical identification of Enterobacteriaceae and other gram negative bacilli. It consists of 20 microtubes containing dehydrated media (each microtube consist of a tube and cupule section). The API 20E system was performed according to the manufacture instructions.

\section{Antibiotic susceptibility testing}

The most frequently isolates were then subjected to antibiotic sensitivity testing by the disc diffusion method on Mueller-Hinton agar(HIMEDIA,India) according to the National Committee for Clinical Laboratory Standards and Manual of Antimicrobial Susceptibility Testing guidelines (NCCLS, 2002; Cheesbrough, 2006; Coyle, 2005; Okonko et al.,2009a,b). Commercially available antimicrobial discs(HIMEDIA,India) were used in the study and included: Nalidixic acid $(30 \mathrm{mcg})$, Doxycycline (30 $\mathrm{mcg}$ ), Erythromycin (15 mcg), Sterptomycin (25 $\mathrm{mcg}$ ), Tetracycline $30 \mathrm{mcg}$ ), Amoxicillin (30 mg), Ciprofloxacin (5 mcg), Gentamicin (10 mcg), Ampicillin (10mcg), Rifampicin (15 mcg), , Norfloxacin $(10 \mathrm{mcg})$ and Lincomycin $(2 \mathrm{mcg})$. Plates were incubated at $35^{\circ} \mathrm{C}$. Zones of inhibition were interpreted as resistant or sensitive using the interpretative chart of the zone diameter of the Kirby - Bauer sensitivity test method as described by Cheesbrough (2006). Interpretation of results was done using the zone of inhibition diameter. Zones of inhibition of _ $18 \mathrm{~mm}$ were considered sensitive, 13$17 \mathrm{~mm}$ intermediate and < $13 \mathrm{~mm}$ resistant (NCCLS, 2002; Cheesbrough, 2006; Coyle, 2005; Okonko et al., 2009a, b).

\section{Results}

Obtained results showed that out of 135 different clinical samples collected from patients visited different hospitals and medical laboratories in Thamar city, YEMEN. A total of 62 blood samples were collected from patients suffered from typhoid fever. A total of 38 urine samples were collected from cases of urinary tract infections and a total of 35 stool samples were collected from cases of diarrhea. Only 54 patients had positive blood culture and 35 patients had positive urine culture. All isolates were identified by the standard biochemical tests and further confirmed by API20E(Figure 1.).

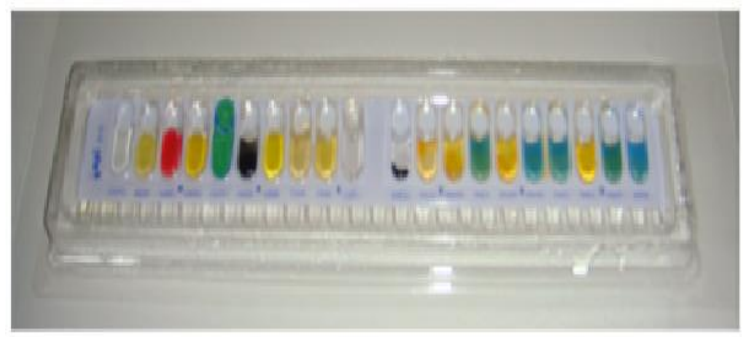

Figure (1): API 20E results for isolated bacteria Salmonella Typhi.

S.typhi, S. paratyphi, and Klebsiella pneumoniae were the most common pathogens isolated from cases of typhoid fever with the percentage of 1 ( $57.4 \%)$, $\mathrm{i}(24.1 \%)$ and $\mathrm{V}(13 \%)$ respectively, from the total number of blood samples(Table 1). Other pathogens were isolated in a relatively few number. The most common urinary pathogenic isolates were E. coI i, and Klebsiella pneumonia with the percentage of $r \cdot(57.1 \%)$ and $1 r(37.1 \%)$ respectively, from the total 
number of urine samples. Escherichia coli, Shigella $S p$. and non-typhoid Salmonella Sp. were the most common pathogens isolated from cases of diarrhea in this study with the percentage of $1 \leq(40 \%), 1$ (31.4\%) and $\Sigma(11.4 ? \%)$ respectively, from the total number of stool samples(Table 1).
Escherchia coli, Salmonella typhi and Klebsiella pneumonia were the most frequently isolated bacteria pathogen from clinical samples with a rate of $34(27.4 \%), 33(26.6 \%)$ and $22(17.7 \%)$ respectively, from the total number of clinical samples( Table 1).

Table 1. Incidence of some pathogenic bacteria in clinical samples.

\begin{tabular}{|c|c|c|c|c|}
\hline \multirow[t]{2}{*}{ Micromicroorganisms } & \multicolumn{4}{|c|}{ No. $(\%)$} \\
\hline & $\begin{array}{c}\text { Blood } \\
(n=54)\end{array}$ & $\begin{array}{c}\text { Urine } \\
(\mathrm{n}=35)\end{array}$ & $\begin{array}{c}\text { Stool } \\
(n=35)\end{array}$ & $\begin{array}{l}\text { Total incidenc(observed growth) } \\
(n=124)\end{array}$ \\
\hline Salmonella typhi & $31(57.4 \%)$ & $\mathbf{0}(0 \%)$ & $2(5.7 \%)$ & $33(26.6 \%)$ \\
\hline Salmonella paratyphi & $13(24.1 \%)$ & $\mathbf{0}(0 \%)$ & $0(0 \%)$ & $13(10.5 \%)$ \\
\hline Escherichia coli & $0(0 \%)$ & $20(57.1 \%)$ & $14(40 \%)$ & $34(27.4 \%)$ \\
\hline Klebsiella pneumonia & $7(13 \%)$ & $13(37.1 \%)$ & $2(5.7 \%)$ & $22(17.7 \%)$ \\
\hline Citrbacteir freundi & $3(5.6 \%)$ & $\mathbf{0}(\mathbf{0 \%})$ & $\mathbf{0}(\mathbf{0 \%})$ & $3(2.4 \%)$ \\
\hline Enterobacter SPP. & $0(0 \%)$ & $0(0 \%)$ & $2(5.7 \%)$ & $2(1.6 \%)$ \\
\hline Shigella SPP. & $\mathbf{0}(\mathbf{0 \%})$ & $\mathbf{0}(\mathbf{0 \%})$ & $11(31.4 \%)$ & $11(8.9 \%)$ \\
\hline Salmonella SPP.. & $0(0 \%)$ & $2(5.7 \%)$ & $4(11.4 ? \%)$ & $6(4.8 \%)$ \\
\hline
\end{tabular}

$\mathrm{N}$ : number of positive samples.

Susceptibility of bacterial isolates(percentage of isolates showing antibiotic resistance) from patients to antibiotics is shown in Table (2). All 33 Salmonella typhi isolates showed high resistance $(100 \%)$ to Lincomycin and Tetracycline whereas $29(87.5 \%)$ and $17(50 \%)$ were resistance to ,Rifampicin and Nalidixic acid, respectively. However, All 33 S.typhi isolates were susceptible $(100 \%)$ to Amoxicillin, Doxycycline,Streptomycin and Gentamycin . Among 33 S. typhi only $24(72.7 \%)$ and $21(62.5 \%)$ were Intermediate resistance to Ciprofloxacin and Norfloxacin, respectively compared with $20(66.7 \%$ )and12(37.5\%) were susceptible to Ampicillin and Nalidixic acid, respectively. As shown in Table (2). all 13 Salmonella paratyphi isolates were resistance $(100 \%)$ to Lincomycin and Tetracycline whereas $11(84.6 \%)$ and $10(76.9 \%)$ were resistance to Streptomycin and Nalidixic acid, respectively. All 13 S. paratyphi isolates were susceptible to Amoxicillin, Doxycycline (100\%) and Gentamycin $(84.6 \%)$. All 34 Escherchia coli isolates showed high resistance(100\%) to Ampicillin,Erythromycin, Lincomycin, Amoxicillin and ,Rifampicin whereas 23 isolates $(67.6 \%)$ were resistance to Ciprofloxacin, Tetracycline, Doxycycline and Streptomycin.
However, 20(58.8\%) and $17(50 \%)$ isolates were resistance to Gentamycin and Nalidixic acid, respectively. As indicated in Table (2). All, 22 Klebsiella pneumoniae isolates showed high resistance rate (100\%) to Erythromycin, Lincomycin ,Rifampicin and Streptomycin and 16(72.7\%) to Amoxicillin and Ciprofloxacin. Also $14(63.6 \%), 12(54.6 \%)$ and $11(50 \%)$ isolates were resistance to Tetracycline, Nalidixic acid and Doxycycline, respectively. In the current study 11 Shigella SPP. isolates showed high resistance (100\%) to Erythromycin, Lincomycin, Rifampicin and Gentamycin whereas 10(90.9\%),9(81.8\%),8(72.7\%) and $6(54.5 \%)$ isolates were resistance to Tetracycline, Ampicillin, Amoxicillin and Doxycycline, respectively. Among 11 Shigella SP. isolates only $8(72.7 \%)$ and $V(63.6 \%)$ were susceptible to Norfloxacin and Ciprofloxacin, respectively. All 6 nontyphoid Salmonella Spp. isolates showed resistance (100\%) to Erythromycin, Lincomycin, Amoxicillin and Rifampicin whereas 4(66.7\%) isolates were resistance to Ampicillin, Tetracycline, Streptomycin and Gentamycin .While, 3(50\%) isolates were resistance to Ciprofloxacin, Nalidixic acid, Doxycycline and Norfloxacin (Table 2.). 
Table 2. Antibiotics sensitivity patterns of some pathogenic isolates from clinical samples.

\begin{tabular}{|c|c|c|c|c|c|c|c|c|c|c|c|c|c|}
\hline \multirow[b]{2}{*}{ Organism } & \multirow{2}{*}{$\begin{array}{c}\text { Susceptibility } \\
\%\end{array}$} & \multicolumn{12}{|c|}{ N\% } \\
\hline & & AMP & $\mathbf{E}$ & $\mathbf{L}$ & AMC & CIP & TE & RIF & NA & DO & $\mathbf{N X}$ & $\mathbf{S}$ & GN \\
\hline \multirow{3}{*}{$\begin{array}{c}\text { Salmonella } \\
\text { typhi }\end{array}$} & Sensitive & $20(66.7 \%$ & $4(12.1 \%)$ & $0(0.0 \%)$ & $33(100 \%)$ & $9(27.3 \%)$ & $0(0.0 \%)$ & $0(0.0 \%)$ & $12(37.5 \%)$ & $33(100 \%)$ & $8(25 \%)$ & $33(100 \%)$ & $33(100 \%)$ \\
\hline & $\begin{array}{c}\text { Intermediate } \\
\text { resistance }\end{array}$ & $13(33.3 \%)$ & $15(44 \%)$ & $0(0.0 \%)$ & $0(0.0 \%)$ & $24(72.7 \%)$ & $0(0.0 \%)$ & $4(12.5 \%)$ & $4(12.5 \%)$ & $0(0.0 \%)$ & $21(62.5 \%)$ & $0(0.0 \%)$ & $0(0.0 \%)$ \\
\hline & Resistant & $0(0.0 \%)$ & $14(43.9 \%)$ & $33(100 \%)$ & $0(0.0 \%)$ & $0(0.0 \%)$ & $33(100 \%)$ & $29(87.5 \%)$ & $17(50 \%)$ & $0(0.0 \%)$ & $4(12.5 \%)$ & $0(0.0 \%)$ & $0(0.0 \%)$ \\
\hline \multirow{3}{*}{$\begin{array}{l}\text { Salmonella } \\
\text { paratyphi }\end{array}$} & Sensitive & $9(71.4 \%)$ & $0(0.0 \%)$ & $\mathbf{0}(0.0 \%)$ & $13(100 \%)$ & $2(15.4 \%)$ & $0(0.0 \%)$ & $0(0.0 \%)$ & $3(23.1 \%)$ & $\mathbf{1 3}(100 \%)$ & $4(30.8 \%)$ & $0(0.0 \%)$ & $11(84.6 \%)$ \\
\hline & $\begin{array}{c}\text { Intermediate } \\
\text { resistance }\end{array}$ & $4(28.6 \%)$ & $6(46.2 \%)$ & $\mathbf{0}(0.0 \%)$ & $0(0.0 \%)$ & $9(69.2 \%)$ & $0(0.0 \%)$ & $5(38.5 \%)$ & $0(0.0 \%)$ & $0(0.0 \%)$ & 7(53.9\%) & $2(15.4 \%)$ & $2(15.4 \%)$ \\
\hline & Resistant & $0(0.0 \%)$ & $7(53.9 \%)$ & $13(100 \%)$ & $0(0.0 \%)$ & $2(15.4 \%)$ & $13(100 \%)$ & $8(61.5 \%)$ & $10(76.9 \%)$ & $0(0.0 \%)$ & $2(15.4 \%)$ & $11(84.6 \%)$ & $0(0.0 \%)$ \\
\hline \multirow{3}{*}{$\begin{array}{c}\text { Escherichia } \\
\text { coli }\end{array}$} & Sensitive & $0(0.0 \%)$ & $\mathbf{0}(0.0 \%)$ & $\mathbf{0}(\mathbf{0 . 0 \%})$ & $0(0.0 \%)$ & $0(0.0 \%)$ & $11(32.4 \%)$ & $\mathbf{0}(0.0 \%)$ & $0(0.0 \%)$ & $0(0.0 \%)$ & $0(0.0 \%)$ & $0(0.0 \%)$ & $14(41.2 \%)$ \\
\hline & $\begin{array}{c}\text { Intermediate } \\
\text { resistance }\end{array}$ & $0(0.0 \%)$ & $0(0.0 \%)$ & $\mathbf{0}(\mathbf{0 . 0 \%})$ & $\mathbf{0}(\mathbf{0}$ & $11(32.4 \%)$ & $\mathbf{0}(0.0 \%)$ & $\mathbf{0}(\mathbf{C}$ & 17 & $.4 \%)$ & $.6 \%)$ & $4 \%)$ & \%) \\
\hline & Resistant & $34(100 \%)$ & $34(100 \%)$ & $34(100 \%)$ & $34(100 \%)$ & $23(67.6 \%)$ & $23(67.7 \%)$ & $34(100 \%)$ & $17(50 \%)$ & $23(67.6 \%)$ & $11(32.4 \%)$ & $23(67.6 \%)$ & $20(58.8 \%)$ \\
\hline \multirow{3}{*}{$\begin{array}{c}\text { Klebsiella } \\
\text { pneumoniae }\end{array}$} & Sensitive & $6(27.3 \%)$ & $\mathbf{0}(0.0 \%)$ & $0(0.0 \%)$ & $\mathbf{0}(0.0 \%)$ & $0(0.0 \%)$ & $7(31.8 \%)$ & $\mathbf{0}(0.0 \%)$ & $4(18.2 \%)$ & $9(40.9 \%)$ & $6(27.3 \%)$ & $0(0.0 \%)$ & $19(86.4 \%)$ \\
\hline & \begin{tabular}{|c|}
$\begin{array}{c}\text { Intermediate } \\
\text { resistance }\end{array}$ \\
\end{tabular} & $8(36.4 \%)$ & $\mathbf{0}(0.0 \%)$ & $\mathbf{0}(\mathbf{0 . 0 \%})$ & $6(27.3 \%)$ & $6(27.3 \%)$ & $1(4.6 \%)$ & $0(0.0 \%)$ & $6(27.3 \%)$ & $2(9.1 \%)$ & $16(72.7 \%)$ & $0(0.0 \%)$ & $0(0.0 \%)$ \\
\hline & \begin{tabular}{|l|} 
Resistant \\
\end{tabular} & $8(36.4 \%)$ & $22(100 \%)$ & $22(100 \%)$ & $16(72.7 \%)$ & $16(72.7 \%)$ & $14(63.6 \%)$ & $22(100 \%)$ & $12(54.6 \%)$ & $11(50 \%)$ & $0(0.0 \%)$ & $22(100 \%)$ & $3(13.6 \%)$ \\
\hline \multirow{3}{*}{$\begin{array}{l}\text { Shigella } \\
\text { SPP. }\end{array}$} & \begin{tabular}{|l|} 
Sensitive \\
\end{tabular} & $0(0.0 \%)$ & $0(0.0 \%)$ & $0(0.0 \%)$ & $3(27.3 \%)$ & $V(63.6 \%)$ & $1(9.1 \%)$ & $0(0.0 \%)$ & $4(36.4 \%)$ & $4(36.4 \%)$ & $8(72.7 \%)$ & $0(0.0 \%)$ & $0(0.0 \%)$ \\
\hline & $\begin{array}{c}\text { Intermediate } \\
\text { resistance }\end{array}$ & $2(18.2 \%)$ & $0(0.0 \%)$ & $\mathbf{0}(\mathbf{0 . 0 \%})$ & $\mathbf{0}(0.0 \%)$ & $4(36.4 \%)$ & $\mathbf{0}(0.0 \%)$ & $0(0.0 \%)$ & $3(27.3 \%)$ & $1(9.1 \%)$ & $8(72.7 \%)$ & $8(72.7 \%)$ & $0(0.0 \%)$ \\
\hline & Resistant & $9(81.8 \%)$ & $11(100 \%)$ & $11(100 \%)$ & $8(72.7 \%)$ & $0(0.0 \%)$ & $10(90.9 \%)$ & \begin{tabular}{|l|}
$11(100 \%)$ \\
\end{tabular} & $4(36.4 \%)$ & $6(54.5 \%)$ & $0(0.0 \%)$ & $8(72.7 \%)$ & $11(100 \%)$ \\
\hline \multirow{3}{*}{$\begin{array}{l}\text { Salmonella } \\
\text { SPP. }\end{array}$} & Sensitive & $0(0.0 \%)$ & $0(0.0 \%)$ & $0(0.0 \%)$ & $0(0.0 \%)$ & $0(0.0 \%)$ & $2(33.3 \%)$ & $0(0.0 \%)$ & $0(0.0 \%)$ & $0(0.0 \%)$ & $0(0.0 \%)$ & $2(33.3 \%)$ & $2(33.3 \%)$ \\
\hline & \begin{tabular}{|c} 
Intermediate \\
resistance
\end{tabular} & $2(33.3 \%)$ & $0(0.0 \%)$ & $\mathbf{0}(0.0 \%)$ & $0(0.0 \%)$ & $3(50 \%)$ & $0(0.0 \%)$ & $0(0.0 \%)$ & $3(50 \%)$ & $3(50 \%)$ & $3(50 \%)$ & $0(0.0 \%)$ & $0(0.0 \%)$ \\
\hline & Resistant & $4(66.7 \%)$ & $6(100 \%)$ & $6(100 \%)$ & $6(100 \%)$ & $3(50 \%)$ & $4(66.7 \%)$ & $6(100 \%)$ & $3(50 \%)$ & $3(50 \%)$ & $3(50 \%)$ & $4(66.7 \%)$ & $4(66.7 \%)$ \\
\hline
\end{tabular}

AMP = Ampicillin, E = Erythromycin, L = Lincomycin, AMC=Amoxicillin, CIP= Ciprofloxacin , TE=Tetracycline, RIF=Rifampicin, NA = Nalidixic acid, Do= Doxycycline, $\mathbf{N X}=$ Norfloxacin, $\mathbf{S}=$ Streptomycin GN = Gentamicin. 


\section{DISCUSSION}

Antimicrobial chemotherapy has conferred huge benefits to human health as a variety of micromicroorganisms that were elucidated to cause infectious diseases are controlled by the proper use of antibiotics. In the 20th century the discovery of antibiotic was viewed that all infectious disease will be conquered in the near future (Power,2004). However, in response to the development of antimicrobial agents, micromicroorganisms, that have acquired resistance to drugs through a variety of mechanisms have emerged and continue to plague human beings. The primary factor responsible for the development and spread of bacterial resistance is the injudicious use of antimicrobial agents(Urassa et.al.,1997).In Yemen, infectious diseases caused by drug resistant bacteria are one of the most important problems in daily clinical practices as observed in the present study. The data generally reflect the seriousness of the antimicrobial resistance among bacterial pathogens in Yemen. Our findings showed that out of 124 bacteria isolated, E. coli (34) and Salmonella typhi (33)) are the most frequently isolated organism, followed by Klebsiella pneumoniae (22), Salmonella paratyphi (13), Shigella Sp.(11) and non-typhoid Salmonella Sp.(6). Salmonella typhi was the commonest Gram-negative microorganisms from blood while E. coli and Klebsiella pneumoniae were the most commonest bacteria from urine also E. coli and Shigella $S p$. were the most commonest bacteria from stool. This finding is in line with the work of Iffat et al., 2011; he showed that $E$. coli was the most frequently isolated organism from urine sample.

All the isolates displayed variable resistance and sensitivity to the antibiotics tested as detailed as shown in Table 2. Strains of Salmonella typhi showed high resistance rate to Lincomycin,Tetracycline, Rifampicin and Nalidixic, Ciprofloxacin and Norfloxacin but were susceptible to Amoxicillin, Doxycycline,Streptomycin and Gentamycin as shown in table 2. Obtained results showed that Salmonella paratyphi isolates were resistance $(100 \%)$ to Lincomycin and Tetracycline whereas $11(84.6 \%)$ and $10(76.9 \%)$ were resistance to Streptomycin and Nalidixic acid but were susceptible to Amoxicillin, Doxycycline and Gentamycin. A study conducted by Krishnan et al 2009. reported that among 359 isolates, the resistance was found against Ampicillin (100\%), Ciprofloxacin $(0.27 \%)$, Nalidixic acid (100\%), and Erythromycin (17.82\%) .Notable results were found with Gentamycin, since no resistance was observed . Krishnan et al., (2009) also observed that 70 and $30 \%$ of the isolates were Salmonella enterica serovar typhi and paratyphi, respectively among which highly sensitive to Ampicillin(84\%) this findings can be correlated with ours but not exactly. The obtained results also correspond and differ with other studies carried out by other researchers (Bhan et.al.,2005,
Lovely et.al.,2012, Stella et.al.,2011,Wain et.al.,1998). The current study showed a high Ampicillin,Erythromycin, Lincomycin, Amoxicillin , Rifampicin, Ciprofloxacin, Tetracycline, Doxycycline, Streptomycin, Nalidixic acid and Gentamycin resistance especially among E. coli and Klebsiella pneumoniae except for Klebsiella pneumoniae that is susceptible to Gentamycin. Similar findings regarding drug resistance patterns of Klebsiella pneumoniae and E. coli have been reported by other researchers (Atif et.al.,2000, Al-nasrawi and Abu almaali.2009, Almaziny, 2014, Iroha et.al.,2013, Eldaif et.al.,2015, Patrícia et.al.,2017)

Moreover, this study indicates that both Shigella Spp. and non-typhoid Salmonella Spp. were resistance to the most antibiotics tested. On the average this result shows that more than $50 \%$ of the microorganism is resistance to the antibiotics (Table 2.).This pattern is comparable to other studies carried out in some other parts of the world (Godwin et.al.,2006, Al-nasrawi and Abu almaali.2009, Eldaif et.al.,2015 , Debas et.al.,2011).The overall prevalence of resistance of micromicroorganisms to antimicrobial agents was notably high in the current study, data reflecting the high level of antibiotic resistance in the country as a whole, when compared to other countries. The variation in the sensitivity pattern and high resistant rate to these commonly used drugs could be attributed to the prevailing usage and abuse, and the common attitude of over-the-counter purchase of the drugs in the areas under study. This further suggests a relationship between antibiotic usage and the level of drug resistance encountered in this study. Selection for drug resistance has been associated with an increased and inappropriate use of antibiotics( Ayliffe,1970). There is an inordinate and irrational use of antimicrobial agents in Yemen and in other developing countries. Multiple factors have led to the prevalence of antibiotic resistance:

1) the wide use of antibiotics due to the high prevalence of infectious diseases, 2) a shortage of physicians,3) selective prescribing due to cost constraints and the pressure of pharmaceutical companies' promotional activities, 4) lack of laboratory support in rural areas, and 5) the difficulties in distributing information regarding antibiotic resistance. An important contributing factor is the deliberate self-administration of antibiotics by patients themselves when they are ill with diarrheal diseases( Kunin et.al.,1987) .Our findings stress the need for distributing reliable information about antibiotic resistance and for ongoing drug-resistance surveillance. Knowledge of drug resistance in bacteria is indispensable for the proper selection of antimicrobial drugs. Yemen, a poor and underdeveloped country, allots a substantial amount of its health-expenditure allocation to the purchase of drugs, especially antibiotics. Resistance studies assist health authorities in the formulation of their own drug policies. They are also important for the general 
practitioner in a remote area who may not have access to microbiology laboratory back-up and hence must depend on the prevailing knowledge of antibioticresistant bacteria. Numerous health organizations world-wide donate large amounts of antibiotics to developing countries like the Yemen to treat diarrhea and other diseases at the community level. The composition of such donations should be based on current knowledge of the common local pathogenic bacteria and their susceptibility patterns.

\section{Conclusion}

High rates of drug resistance were found in most of the isolates studied. In developing countries like Yemen, self-medication is a common practice and this might probably be a major cause of antibiotic resistance in clinical isolates since patients only think of going to the hospitals when they are unable to treat themselves. Inappropriate practices like misuse and abuse of antibiotics and unskilled practitioners can also lead to emergence of resistance in bacteria. Expired antibiotics, self-medication, counterfeit drugs, inadequate hospital control measures can as well promote the development of resistance in clinical isolates. Determining the antimicrobial patterns of the disease causing microorganisms will enable health institutions to restrict the use of antimicrobials and take active measures in preventing the spread of drug resistance in hospitals. However, the insight into the antibiotic susceptibility of clinical isolates profile in any community is very imperative and desirable for effective management of the clinical conditions considering the relative differences in the pattern of susceptibility and resistance of so many pathogens to antibiotics from one locality to another Therefore, it is important for hospitals to improve the processes of care known to impact infection rates. However, the judicious use of antibiotics by health workers and efforts to control procurement and use of antibiotics officially in all localities in Yemen will probably help to limit the increasing rates of multi-drug resistance in pathogens.

\section{References}

Almaziny, M.A.(2014). Isolation, identification, and profile of antibiotic resistance of bacteria in childhood febrile neutropenia patients. European J. of Experimen. Bio, 4(2):1-6.

-Al-nasrawi, A. and abu almaali H.M.(2009). Antibiotic sensitivity patterns of uropathogens isolated from females with urinary symptoms in Karbala. J. of Kerbala Uni. , Vol. 7 No.2 Scientific. -Atif, A. A., Hani, O., Alawayia, M., Hassan, A. M., Abdalla, B. A.,Zein, K., and Hassan, S. H.(2000). Antimicrobial agent resistance in bacterial isolates from patients with diarrhea and urinary tract infection in the Sudan. Am. J. Trop. Med. Hyg., 63(5, 6), pp. 259-263.
-Ayliffe, G.A.J, (1970). Use of antibiotics and resistance in Geddes AM, William J.D, eds. Current Antibiotic Therapy. London: Churchill Livingstone, 53-60.

-Baron, E. and Finegold, S.(1990). Bailey and Scotts Diagnostic Microbiology. 8th ed. Mosby. The C.V.Mosby Company,USA.

-Bhan, M.K, Bahl, R. and Bhatnagar, S. (2005) Typhoid and paratyphoid fever. Lancet, 366 (9487): 749-62.

-Cheesbrough, M. (2006). District Laboratory Practice in Tropical Countries. Cambridge University Press p. 434.

-Chikere, C.B, Chikere, B.O, and Omoni, V.T (2008). Antibiogram of linical isolates from a hospital in Nigeria. Afr. J. Biotechnol. 7 (24): 4359-4363

-Collee, J.G.; Fraser, A.G.; Marmion, B.P. and Simmons, A. (1996) Mackie and McCartney, Practical Medical Microbiology, 14th ed. Churchill Livingston, New York. 978.

-Courvalin, P, and Weber, JT (2005). Antimicrobial drugs and resistance.

Emerg. Infect. Dis., 11: 791-797.

-Coyle, M.B (2005). Manual of Antimicrobial Susceptibility Testing.

American Society for Microbiology Press, Washington D.C. p 25, 39.

-Debas, G., Kibret, M., Biadglegne, F. and B. Abera,.(2011). Prevalence and antimicrobial susceptibility patterns of Shigella SPP. at felege Hiwot Referral Hospital,Northwest Ethiopia. Ethiop. Med. J. Vol. 49, No. 3.

-Eldaif, W.A., Omer, A. and Saeed, N.(2015). In-vitro antimicrobial susceptibility testing of bacteria causing diarrhea in children at Khartoum StateSudan. Indian J. Pharm. Biol. Res. ; 3(1):32-35.

-Farrar, E.W, (1985). Antibiotic resistance in developing countries. J. Infect Dis. 152(6): 11031106.

-Finch, R.G, (1998). Antibiotic resistance. J Antimicrob. Chemother. 42: 125-128.

-Forbes,.B.A., Sahm,,D.F. and Weissfeld,,A.S. (2007) Diagnostic Microbiology, 12thed., MobsyElsevier, Houston, Texas. 324-329, 153, 63,234, 786.

-Godwin, Wilson, Joshy, M. Easow,, Chiranjoy, Mukhopadhyay and P.G. Shivananda.(2006). Isolation and antimicrobial susceptibility of Shigella from patients with acute gastroenteritis in western Nepal. Indian J. Med. Res. 123, : 145-150.

-Iffat J, Rubeena, H.M, Saeed, A (2011). Antibiotic susceptibility patterns of bacterial isolates from patients admitted to a tertiary care hospital in Lahore. Biomedica J. 27:19-23.

-Iroha, R., Nwakeze, E., Afiukwa, N., UduIbiam, O. Nwuzo, C., Oji, E. and Ngwu, N. (2013). Antibiotic susceptibility patterns of bacterial isolates from hospitalized patients in Abakaliki. International Res. J. of Basic and Clinical Studies Vol. 1(4) pp. 46-52. 
-Krishnan, P., Stalin, M. and Balasubramanian, S. (2009) Changing trends in antimicrobial resistance of Salmonella enterica serovar typhi and salmonella enterica serovar paratyphi A in Chennai. Indian J. Pathol. Microbiol., 52: 505-8.

-Kunin, CM, Lipton, HL, Tupasi, T, Sacks, T, Scheckler, WE, Jivani, A, Goic, A., Martin, R.,R, Guerrant R.L, Thamlikitkul, V, (1987). Social, behavioral and practical factors affecting antibiotic use worldwide: report of Task Force 4. Rev Infect. Dis. 9 suppl. 3:S270-S285.

-Lovely, A., Munir, H. and Zakaria, A.(2012). Present status and antibiotic sensitivity pattern Of Salmonella typhi And S. Paratyphi in different age group hospitalized patients in dhaka city, Bangladesh. J. of Pharm. and Bio. Scien. 22783008. Volume 4, Issue 3PP 27-30.

-National Committee for Clinical Laboratory Standards (NCCLS) (2002). Performance standards for antimicrobial susceptibility testing: twelfth informational supplement. NCCLS document M100-S12. PA, USA.

-Okonko, I.O, Donbraye-Emmanuel, O.B, Ijandipe, LA, Ogun, AA, Adedeji, AO, Udeze, AO (2009a). Antibiotics sensitivity and resistance patterns of uropathogens to nitrofurantoin and Nalidixic Acid in pregnant women with urinary tract infections in Ibadan, Nigeria.Middle-East J. Sci. Res. 4 (2): 105-109

-Okonko, IO, Soleye, FA, Amusan, T.A, Ogun, A.A, Ogunnusi, T.A, Ejembi, J,Egun, O.C, Onajobi, B.I (2009b). Incidence of Multi-Drug Resistance (MDR) Microorganisms in Abeokuta, Southwestern Nigeria. Global J. Pharmacol. (in press).

-Patrícia, L. d.; Caroline, S. P.; Lisandra, D. R.; Guilherme, B. C.; Roger, T. F.; Carolina, P. S.; Luiz, M. F.; Francisco, J.; Edilberto, N. M.;
Teresa, C. F. and Paula, P. M.(2017). Antimicrobial susceptibility profile of enterotoxigenic and enteropathogenic Escherichia coli isolates obtained from fecal specimens of children with acute diarrhea. J. Bras. Patol. Med. Lab., v. 53, n. 2, p. 115-118.

-Parry, MF, (1989). Epidemiology and mechanism of antimicrobial resistance. Am. J. Inf. Control 17(5): 286-294.

-Power, JH (2004). Antimicrobial drug development: The past, present and future. Clin. Microbio. Infect. 10(Suppl. 4): 23-31

-Rahal, K, Wang, F, Schindler, J. Rowe B, Cookson B, Huovinen P, Martin A, Lalitha MK, Semina N, Kronvall G, Guzman M, (1997). Reports on surveillance of antimicrobial resistance in individual countries. Clin. Infect. Dis. 24 Suppl. 1: S169-S175.

-Stella, S., Moses, B., Muinah, F., Helen, G., T., Emmanuel, O., A., Kehinde, A. A., Toun, F., Rob, P., Theresa, A., H. and Henk, S., L. (2011).Application of a point-of-care test for the serodiagnosis of typhoid fever in Nigeria and the need for improved diagnostics. J. of Infect. Develop. Count.,5(7):520-526.

-Tenvor, F.C., and Hughes, J.M., (1996). The challenges of emerging infectious diseases: development and spread of multiply-resistant bacterial pathogens. JAMA 275(4): 300-304.

-Urassa, W, Lyamuya, E, and Mhalu, F., (1997). Recent trends on bacterial resistance to antibiotics. East. Afr. Med. J. 74(3): 129-133.

-Wain, J.; Diep, T.S.; Ho, V.A.; M.Walsh,A; Hoa, N.T; M.Parry. C. and White, N.(1998). Quantitation of bacteria in blood of typhoid fever patients and relationship between Counts and Clinical Features transmissibility, and antibiotic resistance. J. of Clin. Microbiol., 1683-1687. 